\title{
The Application of Electrospray Tandem Mass Spectrometry for de novo Sequencing of Reduced Insulins
}

\author{
Xichen Gao \\ Gan \& Lee Pharmaceutical, Ltd., Beijing, China \\ Email: gaoxichen@live.com
}

How to cite this paper: Gao, X.C. (2019) The Application of Electrospray Tandem Mass Spectrometry for de novo Sequencing of Reduced Insulins. Journal of Biosciences and Medicines, 7, 135-150.

https://doi.org/10.4236/jbm.2019.77011

Received: June 21, 2019

Accepted: July 26, 2019

Published: July 29, 2019

Copyright ( 2019 by author(s) and Scientific Research Publishing Inc. This work is licensed under the Creative Commons Attribution International License (CC BY 4.0).

http://creativecommons.org/licenses/by/4.0/

Open Access

\begin{abstract}
Insulin, a blood glucose level mediator, is the mainstream therapeutic choice for diabetes patients. Since patent protection for many originator products is about to expire, manufacturers of follow-on insulin are determined to get their products authorized. According to regulations, a fundamental requirement for biosimilar compounds is that the chemical structure should be the same as that of the originator drug. Hence, the application of qualitative analysis for insulin products is essential during the production and development of biosimilars. In this study, the electrospray tandem MS/MS based de novo sequencing method was developed and validated by analyzing two insulin products with similar primary structures, namely recombinant human insulin and insulin aspart. The results indicated that the complete sequences of both reduced insulins are largely identifiable, although differentiation between leucine and isoleucine is not achieved. More importantly, the observed mass accuracy was substantial. The method can, therefore be applied to quality control and drug development.
\end{abstract}

\section{Keywords}

Insulin, Tandem Mass Spectrometry, Electrospray, de novo Sequencing

\section{Introduction}

Diabetes is currently an incurable and potentially life-threatening disorder that occurs in patients whose pancreas $\beta$ cells cannot secrete a sufficient amount of insulin into the blood, resulting in elevated blood glucose levels. In severe cases, the gland could lose its function entirely. High blood sugar levels cause severe impairments in all the body's organs, particularly the kidneys, the nervous sys- 
tem, and the visual system. Diabetes affected approximately 382 million people globally in 2013, and this figure is expected to reach 592 million by 2035 [1]. Another research report from the International Diabetes Federation (IDF) demonstrates that around 415 million people suffered from diabetes in 2015 and that this number will reach 642 million by 2040, including a considerable number of patients from middle- and low-income countries [2]. Since diabetes patients require continuous treatment, the global cost associated with diabetic treatment reached $\$ 673 \mathrm{~b}$ in 2015, and is expected to exceed $\$ 802 \mathrm{~b}$ by 2040 [2]. As the primary therapeutic solution for both type I and type II diabetes, a growing number of insulin products have been developed since the first patient was successfully treated with animal-origin insulin in 1922 [3]. It is expected that the global insulin market will reach $\$ 32$ billion in 2019 [4]. The heavy financial burden associated with diabetic treatment has been a common obstacle for many countries, particularly developing countries. The good news is that the patents for a series of insulin products are due to expire shortly, which represents an opportunity to provide patients with access to more affordable follow-on drugs [5].

However, the manufacture of biomedicines is more complicated than that of chemical drugs. Based on the definition of "biosimilars" given by the European Medicines Agency (EMA), a biosimilar is an exact copy of an approved reference drug, and the consistency in physiochemical characteristics, safety, and clinical efficacy between the biosimilar and the innovator product must be evaluated [6]. Due to the proprietary manufacturing process patented by the innovator, manufacturers of biosimilars must develop independent expression systems. Merely copying the chemical and biological properties of an originator drug does not ensure the new compound's safety and bio-equivalency [7]. One of the biggest safety concerns is immunogenicity, which can trigger immunological reactions or compromise the drug's efficacy. Potential immunoreactions include insulin allergies, antibody-mediated insulin resistance, and others [8] [9]. The occurrence of immunoreactions is attributable to many factors, such as the drug's amino acid sequence, spatial structure, and other characteristics that are influenced by the manufacturing process [5]. Three different manufacturing processes based on recombinant DNA technology have been developed, two of which use $E$. coli as an expression system, while the third uses yeast cells [10]. The detailed manufacturing process was summarized by [11]. The author stresses that minor changes in environmental and processing conditions could result in altered product structures which could, in turn, result in a latent potential for immunogenicity. For instance, a series of structural changes could occur if production or storage is not performed correctly, including oxidation, deamidation, and polymer formation [12]. Therefore, robust quality control techniques are indispensable [13].

To guarantee safety and efficacy, a drug's amino acid sequence must be analyzed using advanced analytical techniques (e.g., peptide mapping, mass spec- 
trometry, and in-situ analysis) to ensure that the amino acid structure is consistent with that of the originator drug within single batches and between batches [14]. As a result of incredible advances in mass spectrometry (MS) technology, MS-based de novo sequencing plays an increasingly crucial role in the identification of proteins. De novo sequencing is emphasized due to its application of soft ionization technology, the broad selection of mass spectrometers that supports it, and the highly automated data manipulation that it offers [15].

In this study, the amino acid structures of recombinant human insulin and recombinant insulin aspart were determined using the tandem MS/MS ESI-QToF system. Data manipulation was performed using Unify. Furthermore, identification accuracy was conducted via mass error calculation. By doing so, the potential utilization of the method in the quality control of insulin biosimilars and drug development could be evaluated.

\section{Materials and Methods}

\subsection{Chemicals and Reagents}

The reference standards of insulin human and insulin aspart were purchased from USP (100 mg for insulin human and $7.62 \mathrm{mg}$ for insulin aspart; MD, USA). Acetonitrile (LC/MS grade) was obtained from Fisher Chemical (Geel, Belgium). Formic acid was HPLC grade and purchased from ROE (DE, USA). Methanol (HPLC grade) was bought from Sigma Aldrich (MO, USA). The HPLC grade isopropanol was got from CNW (Anpel Laboratory Technologies, Shanghai, China). Tris (2-carboxyethyl) phosphine hydrochloride (TCEP; Sigma Aldrich, MO, USA) was used as the reductant in the reduction of disulfide bonds. The deionized water used in the experiment was produced by MilliQ water system (Millipore S.A.S., Molsheim, France).

\subsection{Sample Preparation}

The insulin stock solutions $(0.1 \mathrm{mg} / \mathrm{ml})$ were prepared by dissolving $5 \mathrm{mg} \mathrm{hu}$ man insulin and insulin aspart in $50 \mathrm{ml} 0.1 \%$ formic acid solution, respectively. The human insulin sample to be reduced was prepared by adding around 28.7 $\mathrm{mg}$ TCEP $(10 \mathrm{mM})$ into an empty $15 \mathrm{ml}$ centrifuge tube, followed by transferring $0.5 \mathrm{ml}$ insulin human stock solution to the tube, and then adding $0.1 \%$ formic acid solution to $10 \mathrm{ml}$. subsequently, the solution was mixed thoroughly, until the TCEP was fully dissolved. The preparation of the insulin aspart sample to be tested was same as that of the human insulin. Both insulin samples were incubated at $55^{\circ} \mathrm{C}$ in water bath for $60 \mathrm{~min}$ to fully cleave the disulfide bonds. After cooling to room temperature, the samples were injected and analyzed directly.

\subsection{Chromatographic and Mass Spectrometric Settings}

LC-MS/MS analysis was conducted by employing Acquity I Class Plus UPLC (Waters, MA, USA) coupled with Vion IMS QToF (Waters, MA, USA). The samples were kept cooled at $4^{\circ} \mathrm{C}$ in the autosampler, and the column oven tem- 
perature was $40^{\circ} \mathrm{C}$. A Waters Acquity UPLC protein BEH C4 column $(50 \times 2.1$ $\mathrm{mm}, 1.7 \mu \mathrm{m}, 300 \AA$ ) was installed, which was highlighted by the significantly reduced retention of protein in column compared to C18 ligand column. The mobile phase A was $0.1 \%$ formic acid in water $(\mathrm{v} / \mathrm{v})$, and acetonitrile containing $0.1 \%$ formic acid was used as mobile phase B. The flow rate was set at $0.4 \mathrm{ml} / \mathrm{min}$. $10 \mu \mathrm{l}$ sample was injected for each analysis. The gradient initiated at $80 \%$ solvent A, and decreased to $70 \%$ within 3 min, followed by a linear gradient from $70 \%$ down to $40 \%$. The fraction of solvent A was kept for $0.5 \mathrm{~min}$, and then the column was re-equilibrated at the starting conditions from $7.6 \mathrm{~min}$ to $10 \mathrm{~min}$.

Positive electrospray ionization (ESI) was used to generate the parental ions. The acquisition mode was $\mathrm{MS}^{\mathrm{E}}$, which was a unique mode provided by Waters. The mass scan ranged from $500 \mathrm{~m} / \mathrm{z}$ to $2000 \mathrm{~m} / \mathrm{z}$. The scan time was $0.2 \mathrm{~s}$, during which the low collision energy of CID was set at $6 \mathrm{eV}$, and the high collision energy ramp started from $20 \mathrm{eV}$ to $30 \mathrm{eV}$. The desolvation temperature and source temperature were $400^{\circ} \mathrm{C}$ and $100^{\circ} \mathrm{C}$, respectively. The desolvation gas flow rate and cone gas flow rate were $650 \mathrm{~L} / \mathrm{H}$ and $50 \mathrm{~L} / \mathrm{H}$, respectively. The capillary voltage was $3.2 \mathrm{kV}$. The data acquisition and manipulation were carried out utilizing Unify 1.9.3.

\section{Results and Discussion}

\subsection{The Reduction of Disulfide Bonds}

Insulin consists of two peptide chains (namely A-chain and B-chain) connected via two interchain disulfide bonds. An intrachain disulfide bond also bridges the $7^{\text {th }}$ cysteine and the $11^{\text {th }}$ cysteine within the A-chain. Since disulfide bonds are challenging to break via collision-induced ionization (CID), it is necessary to cleave the bond to obtain detailed debris ions [16]. In this study, recombinant human insulin and insulin aspart was reduced using TCEP and incubation at $55^{\circ} \mathrm{C}$ over a period of $60 \mathrm{~min}$. The underlying functional mechanism of TCEP was outlined decades ago [17] [18]. The reduction is characterized by the reversible formation of a thiophosphonium compound, followed by the irreversible generation of thiols and phosphine oxide. The results showed that, under these conditions, both insulins could be nearly fully cleaved. Two isolated peptide chains for each insulin were detected and separated using UPLC. As shown in Figure 1, human insulin's A- and B-chains eluted at $3.24 \mathrm{~min}$ and $2.59 \mathrm{~min}$, respectively. Interestingly, the retention times of insulin aspart's free A-chain and B-chain (Figure 2) were almost identical with that of human insulin since the amino acid sequences of human insulin's A-chain and insulin aspart are identical, and the B-chain's primary peptide structures for both human insulin and insulin aspart are very similar.

The peaks were identified based on the parent ion clusters, and the combined corresponding spectra for human insulin and insulin aspart are shown in Figures 3-6. Generally, intact insulin molecules can be adequately ionized using ESI, and multiple protonated ions (ranging from four-fold to six-fold) are observable [16]. 


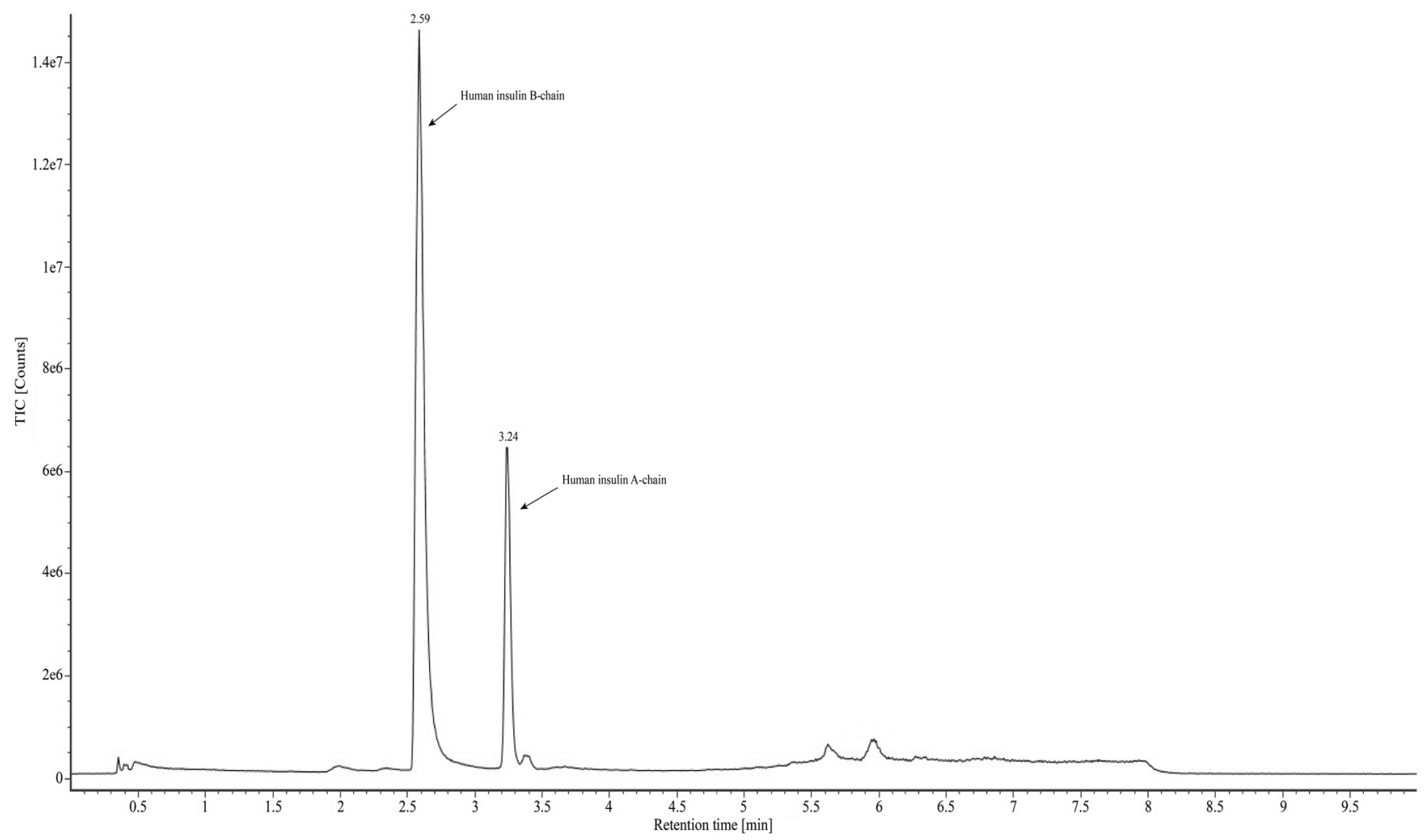

Figure 1. The reduction of intact recombinant human insulin at $55^{\circ} \mathrm{C}$ for 60 min using TCEP. Both peptide chains were nearly completely cleaved, and the isolated peptide chains were distinguishable.

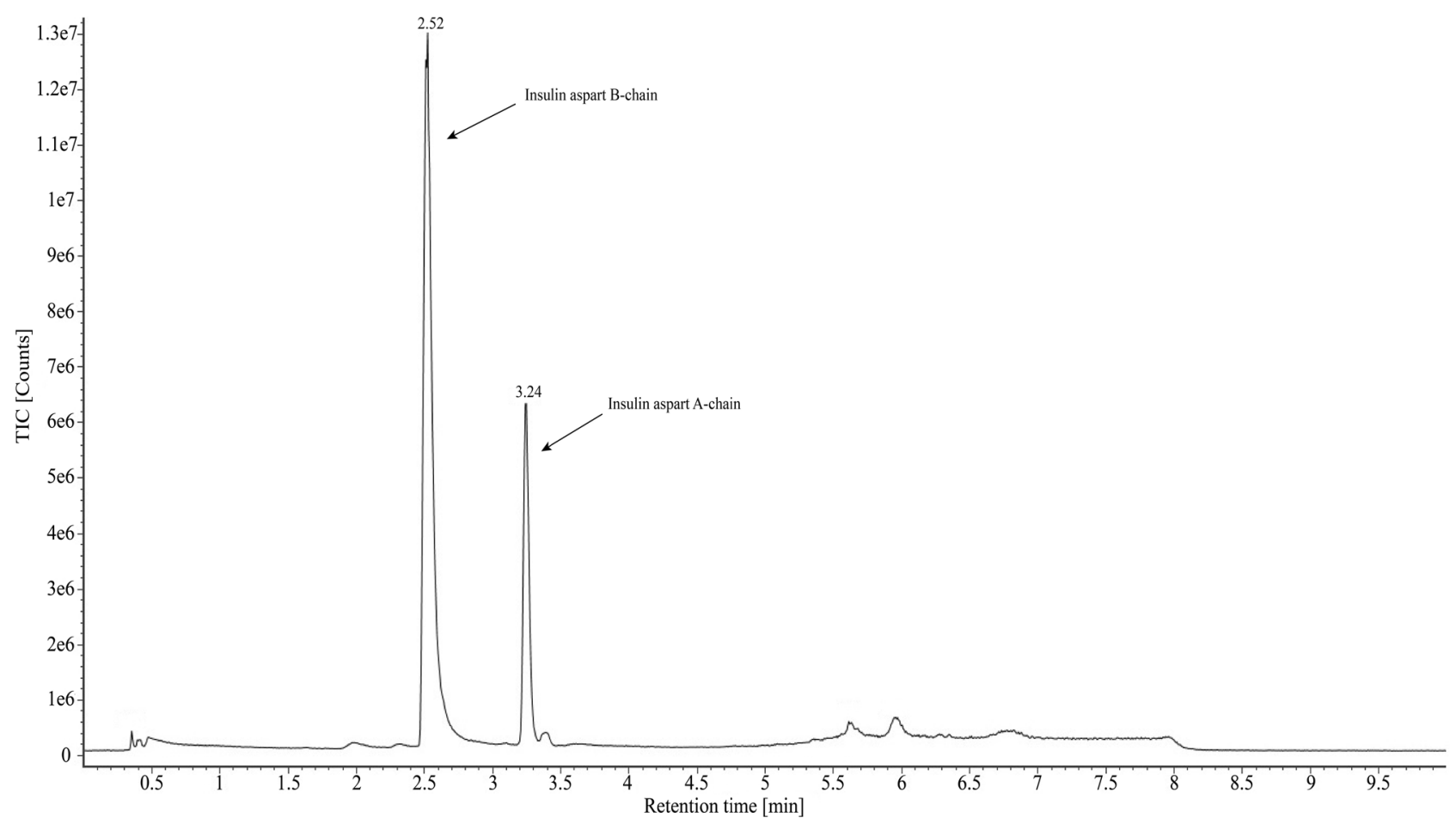

Figure 2. The reduction of intact recombinant aspart insulin at $55^{\circ} \mathrm{C}$ for 60 min using TCEP. Both peptide chains were nearly completely cleaved, and the isolated peptide chains were distinguishable. 


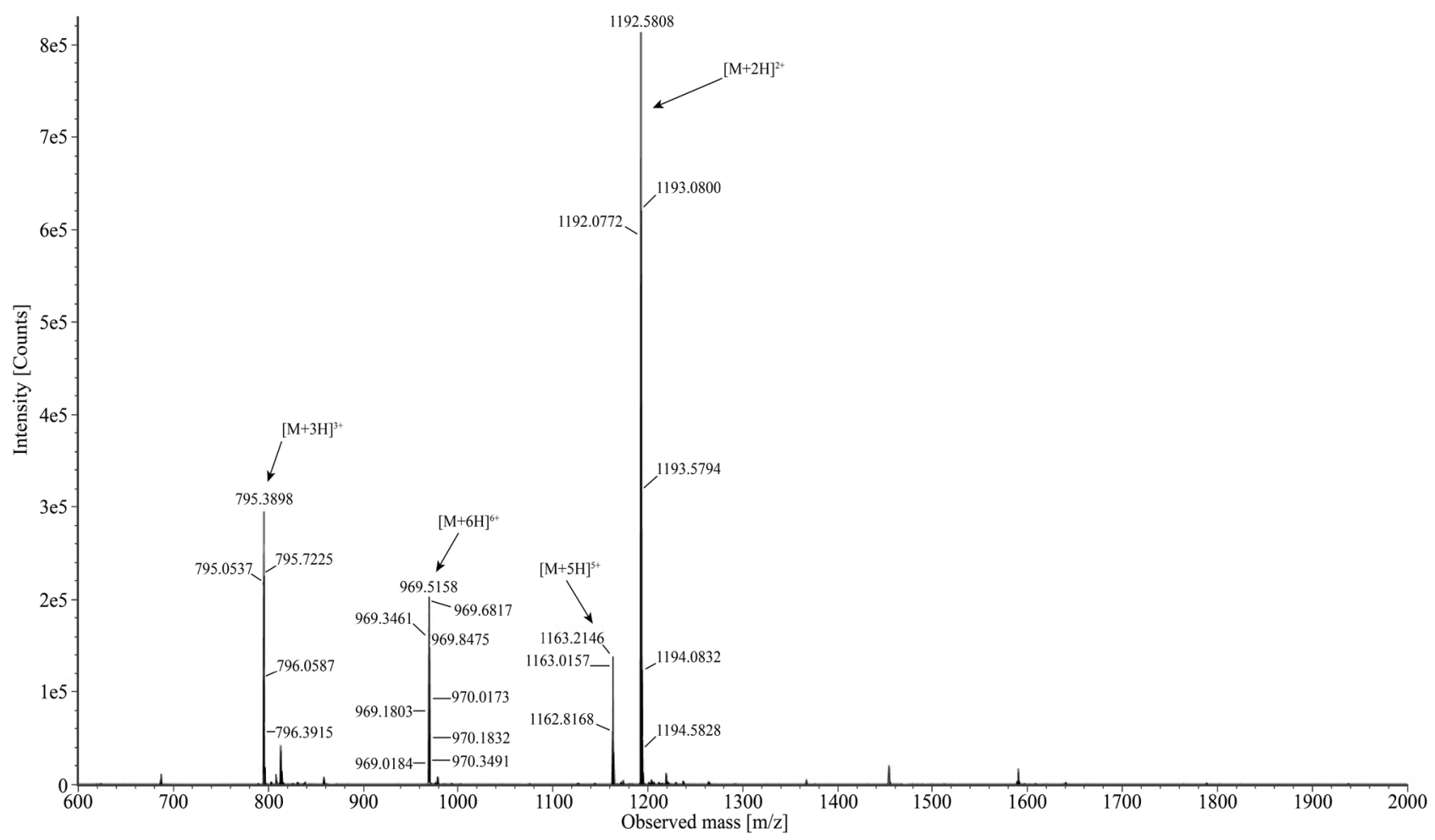

Figure 3. The precursor ion clusters for the human insulin A-chain. The doubly and triply charged precursor ion clusters of A-chain were observed. However, the quintuply and sextuply charged precursor ions of the intact human insulin coeluted with the human insulin A-chain.

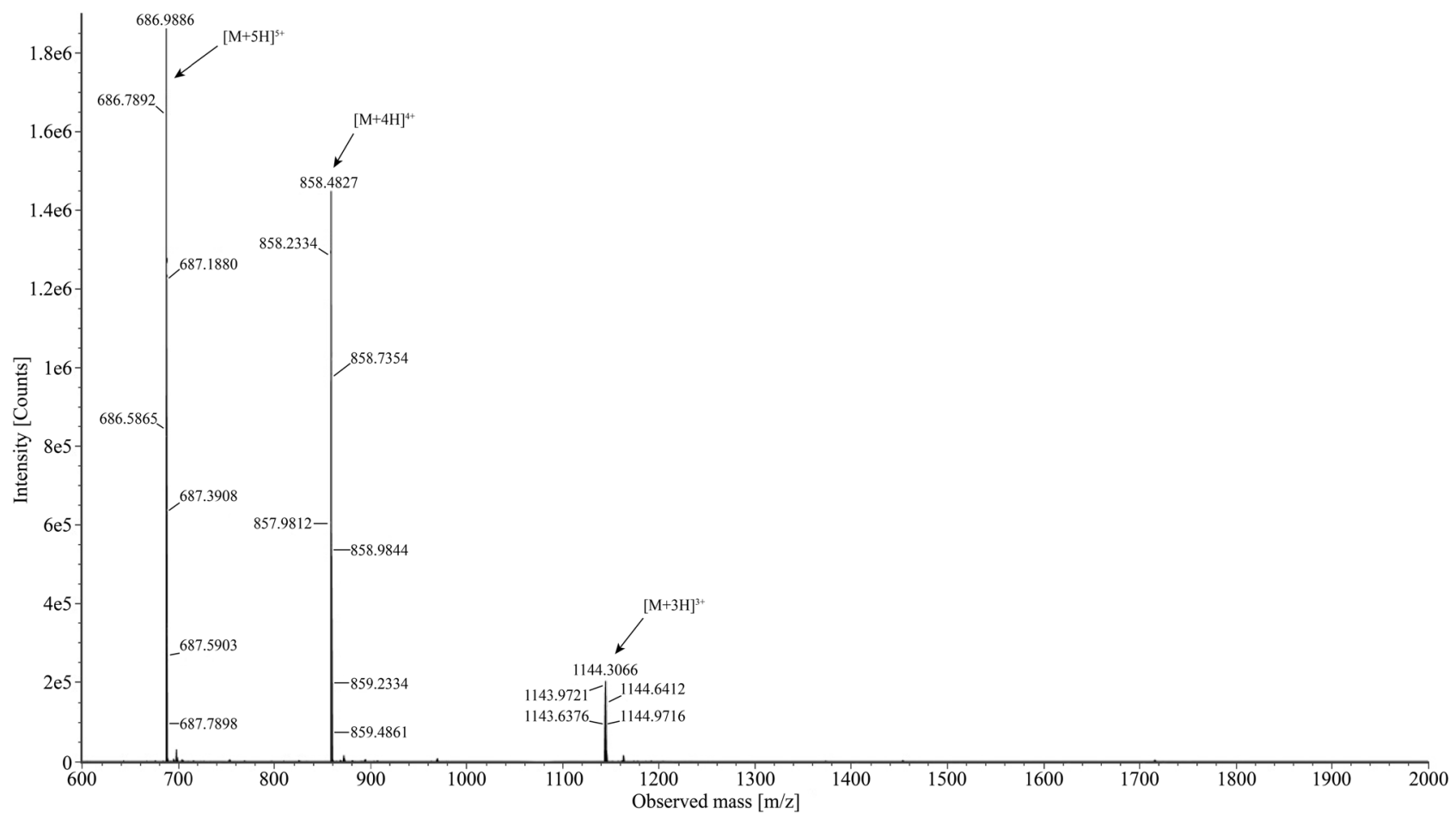

Figure 4. The precursor ion clusters for the human insulin B-chain. The triply, quadruply and quintuply charged precursor ions of B-chain were observed. 


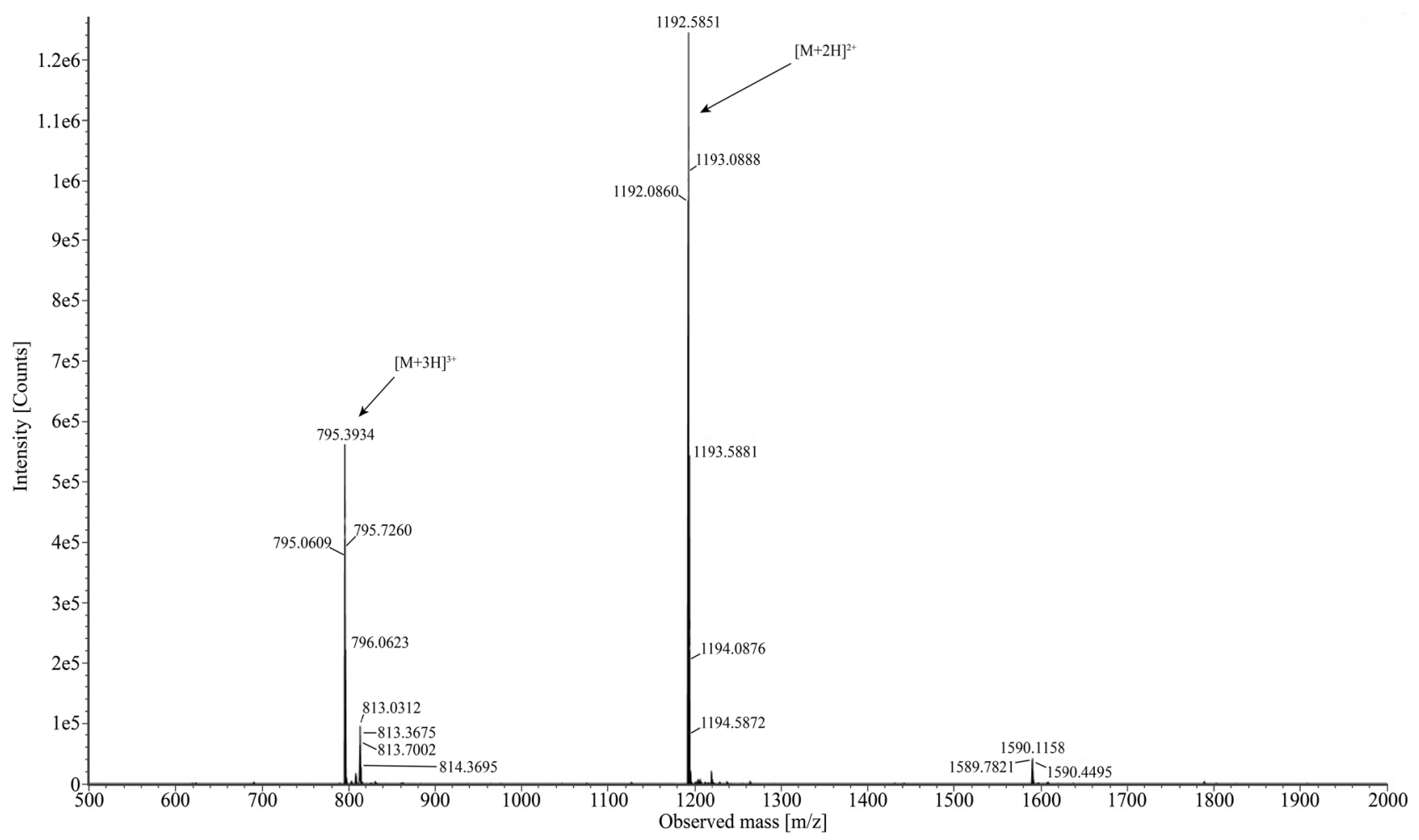

Figure 5. The precursor ion envelopes for the isolated A-chain of insulin aspart. The doubly and triply charged ions of A-chain were obtained.

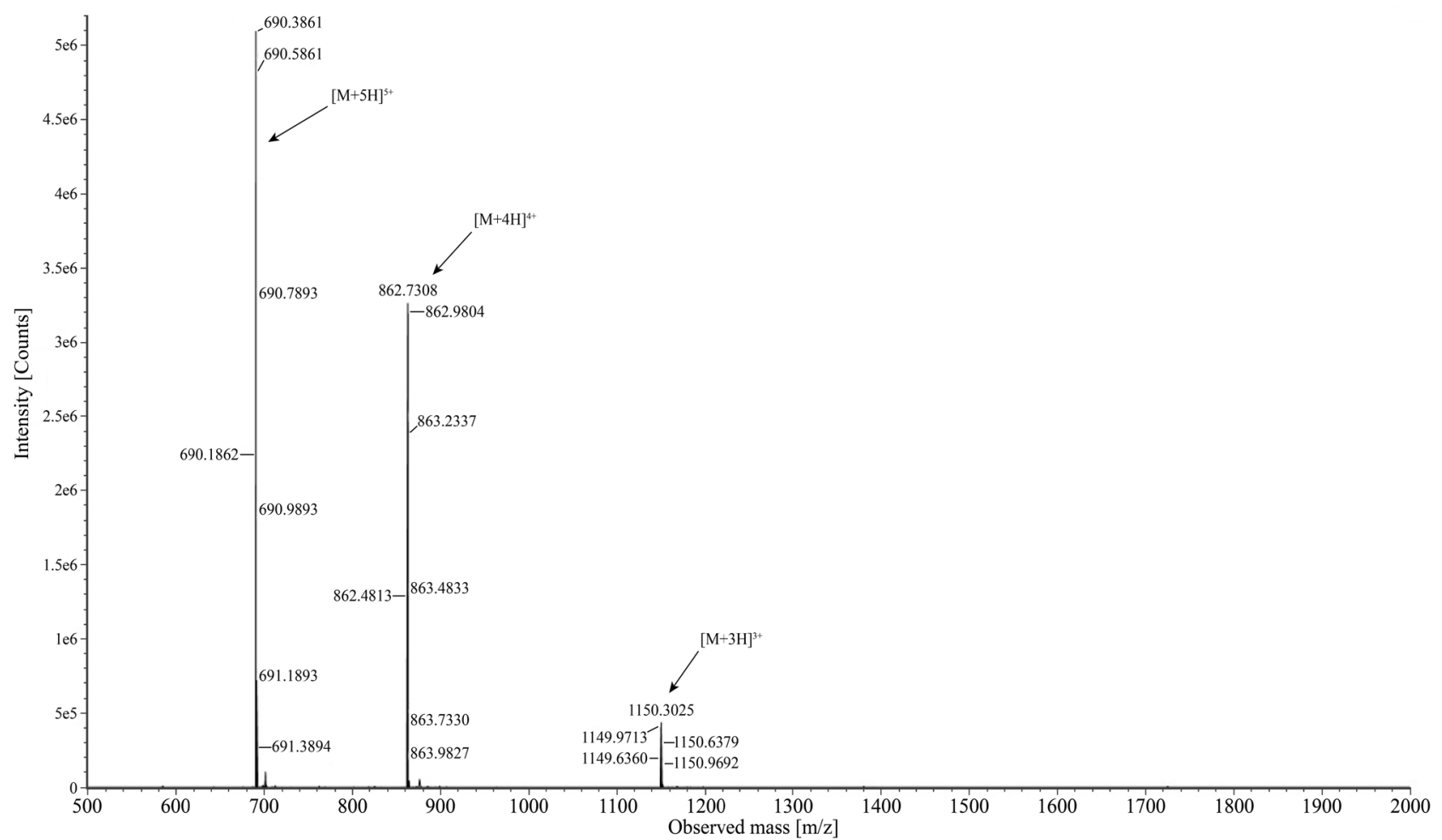

Figure 6. The precursor ion envelopes for the isolated B-chain of insulin aspart. The triple-, quadruple- and quintuple-fold protonated precursor ions of B chain were obtained. 
As depicted in Figure 3, the double- and triple-charged precursor ion clusters of the A-chain were detectable. However, the coexistence of the quintuple- and sextuple-charged precursor ions of intact human insulin was also observed, suggesting that a certain amount of intact insulin was not reduced using TCEP. On the contrary, human insulin was absent in the B-chain peak, although the triple-, quadruple-, and quintuple-fold protonated precursor ions were identifiable in the B-chain (Figure 4).

Regarding insulin aspart, the double- and triple-charged ion clusters of the A-chain and the triple-, quadruple-, and quintuple-charged clusters of the B-chain are shown in Figure 5 and Figure 6. Simultaneously, intact insulin aspart was not detected within the two peaks.

Many researchers have reduced insulin's disulfide bonds via TCEP under various experimental conditions. For instance, Hjorth, Hubálek et al. investigated high molecular weight proteins in a human insulin product manufactured by Novo Nordisk A/S [12]. The researchers reduced the disulfide bond using 4.8 $\mathrm{mM}$ TCEP at $37^{\circ} \mathrm{C}$ for $30 \mathrm{~min}$. The sample's peaks contained partially reduced product, which is consistent with previous research findings (data not displayed). Gray, claiming to have successfully cleaved insulin, performed the reduction at $60^{\circ} \mathrm{C}$ for $10 \mathrm{~min}$ using $10 \mathrm{mM}$ TCEP [19]. According to research conducted by Thevis, Thomas et al., human insulin could be reduced using 10 $\mathrm{mM}$ TCEP at $60^{\circ} \mathrm{C}$ for $10 \mathrm{~min}$ [20]. However, the results did not indicate whether the disulfide bond was fully cleaved. Although partially reduced product may be present, its effect on the de novo sequencing of free peptide chains can be safely disregarded in this study.

\subsection{The Primary Structure of Free Insulin Peptide Chains}

In this study, a hybrid quadruple ToF mass spectrometer coupled with CID was employed to evaluate the amino acid sequence of isolated insulin peptide chains. The fragmentation pattern observed in CID is the typical N- and C-terminus fragmentation described by Biemann and Roerpstorff [21]. Therefore, the amino acid structure was determined through the recognition of $b$ - and $y$-debris ions, based on the secondary mass spectra. The data processing was completed automatically in Unify.

\subsubsection{Recombinant Human Insulin}

To acquire copious fragment ions, a collision-energy ramp $(20 \mathrm{eV}-30 \mathrm{eV})$ was used inside the CID compartment. The spectrum results were especially useful, but interpreting the data was problematic. Unify was used to post-analyze the spectrum results. Through the assignment of $y$ - and b-type ions, the entire sequences of two free peptide chains were pinpointed. The complete sequence exposure of human insulin (A-chain) is indicated in Figure 7. The pinpointed daughter ions comprised 15 y-ions and 16 b-ions. However, the Gly-Lle/Leu-Val-Glu-Gln sequence was unconfirmable, conceivably due to the collision energy not being sufficiently high to fully cleave the peptide inside the CID chamber. 
Figure 8 demonstrates the fragmentation ion spectrum (fluctuating between $1000 \mathrm{~m} / \mathrm{z}$ and $1085 \mathrm{~m} / \mathrm{z}$ ). Some isotopic envelopes have not yet been established, although virtually all the essential clusters are assignable. Daughter ion clusters were observable at $1016.46 \mathrm{~m} / \mathrm{z}, 1028.42 \mathrm{~m} / \mathrm{z}, 1034.47 \mathrm{~m} / \mathrm{z}, 1046.43 \mathrm{~m} / \mathrm{z}$ (respectively

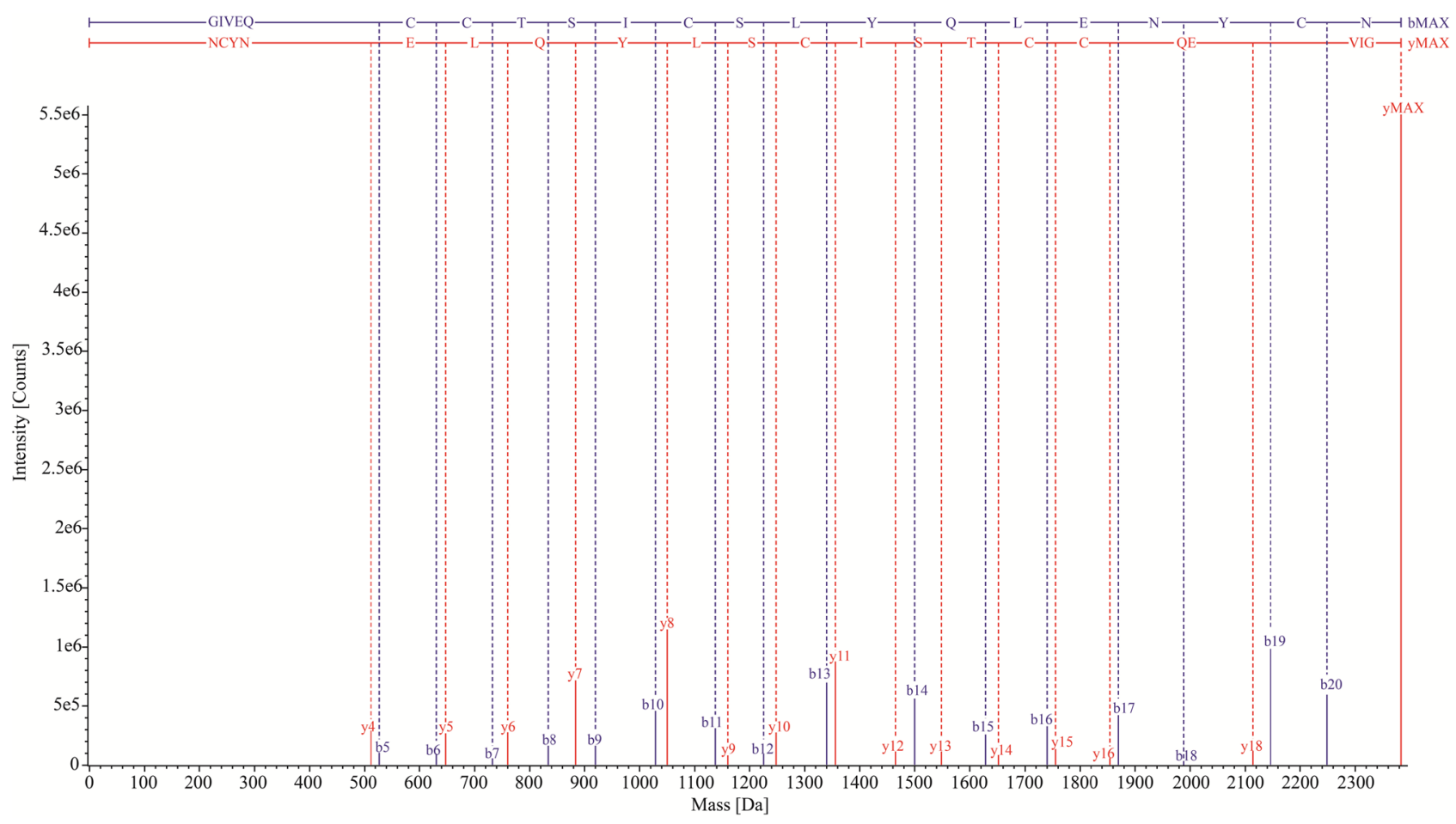

Figure 7. The assignment of $\mathrm{b}$ and $\mathrm{y}$ type ions of human insulin A-chain peptide.

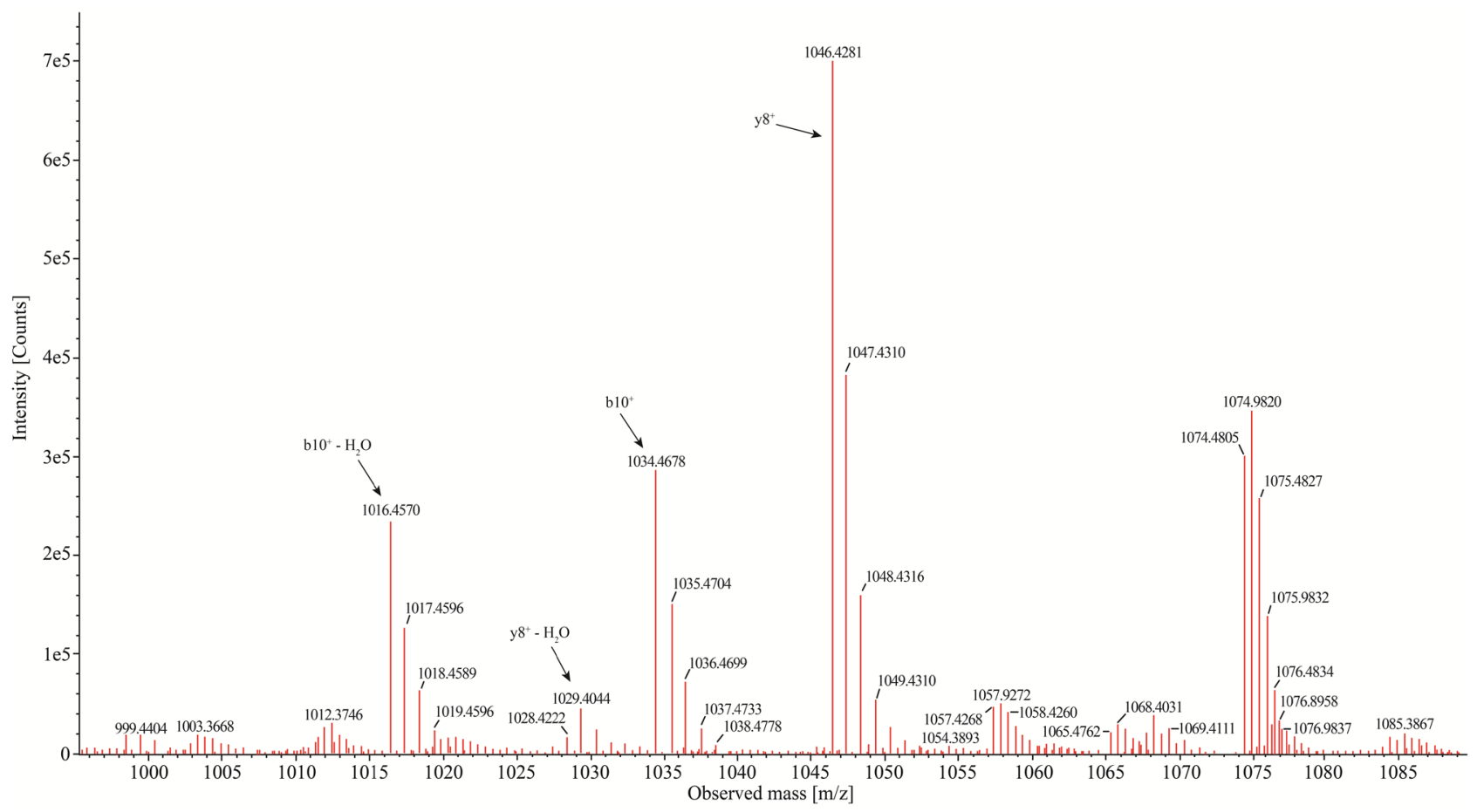

Figure 8. The assignment of daughter ion clusters for free human insulin A-chain ranging between $1000 \mathrm{~m} / \mathrm{z}$ and $1085 \mathrm{~m} / \mathrm{z}$. 
signifying $\mathrm{b} 10^{+}-\mathrm{H}_{2} \mathrm{O}, \mathrm{y}^{+}-\mathrm{H}_{2} \mathrm{O}, \mathrm{b} 10^{+}$, and $\mathrm{y} 8^{+}$). Conversely, the ion clusters observed at $1057.43 \mathrm{~m} / \mathrm{z}, 1068.40 \mathrm{~m} / \mathrm{z}, 1074.48 \mathrm{~m} / \mathrm{z}$, and $1085.39 \mathrm{~m} / \mathrm{z}$ remain unidentified.

Likewise, the fragmentation ion mapping for B-chain human insulin indicated that nearly the entire B-chain peptide sequence was pinpointed, although two unassigned gaps were detected between the $3^{\text {rd }}$ and $4^{\text {th }}$ residues, and the $28^{\text {th }}$ and $30^{\text {th }}$ residues (Figure 9).

As shown in Figure 10, both single- and double-charged daughter ions were created. Neutral $\mathrm{H}_{2} \mathrm{O}(18 \mathrm{Da})$ and $\mathrm{NH}_{3}(17 \mathrm{Da})$ losses from y- and b-daughter ions were identified as satellite ions. Between $590 \mathrm{~m} / \mathrm{z}$ and $715 \mathrm{~m} / \mathrm{z}$, two double-charged b-type ions, two-double charged y-ions, and one single-charged $\mathrm{y}$-ion were observed (determined as $\mathrm{b} 11^{2+}, \mathrm{b} 12^{2+}, \mathrm{y}^{1} 1^{2+}, \mathrm{y}^{2} 2^{2+}$, and $\mathrm{y} 5^{+}$), in addition to the satellite ions. However, for both free peptide chains, some isotopic clusters could not be allocated. For now, the differentiation of leucine and isoleucine is still problematic.

\subsubsection{Recombinant Insulin Aspart}

Insulin aspart is a recombinant human insulin analog, where the proline (in the $28^{\text {th }}$ position) in B-chain human insulin is substituted with aspart.

Unlike the results garnered from A-chain human insulin, the occurrence of $\mathrm{y} 18^{+}$and $\mathrm{y} 19^{+}$ions suggests that the $18^{\text {th }}, 19^{\text {th }}$ and $20^{\text {th }}$ amino acid sequences are determinable (Figure 11). However, distinguishing between leucine and isoleucine remains challenging. In the range of $1445 \mathrm{~m} / \mathrm{z}-1535 \mathrm{~m} / \mathrm{z}$, all the critical ion clusters were allocated, including $\mathrm{y}^{2} 2^{+}, \mathrm{b} 14^{+}$, and the observed satellite ions (Figure 12).

The fragmentation ion mapping for B-chain recombinant insulin aspart shows two undetermined gaps (i.e., Asn-Gln and Thr-Asp-Lys; Figure 13). Thevis, Thomas et al. created b4 and y2 ions through an ESI-CID-Qtrap configuration with a high-collision offset voltage of $70 \mathrm{~V}$ [22], suggesting that high-collision energy was necessary for superior fragmentation behavior in insulin aspart. It is important to note that isoleucine and leucine remain undifferentiated. Thomas, Schänzer et al. attempted to pinpoint molecules with matching molecular masses by way of adding another dimension of separation (e.g., using an ion mobility spectrometer) [23]. Using an ion mobility spectrometer, Asbury and Hill Jr. claimed to have obtained a 0.668 resolution between leucine and isoleucine [24]. Therefore, additional research with the tandem MS/MS system is required to differentiate between leucine and isoleucine.

As shown in Figure 14, double- and triple-charged ions were observed in the spectrum. In the range of $895 \mathrm{~m} / \mathrm{z}-1000 \mathrm{~m} / \mathrm{z}$, almost all the important isotopic envelopes were assignable (including $\mathrm{b} 16^{2+}, \mathrm{b} 17^{2+}, \mathrm{y} 15^{2+}-\mathrm{y} 17^{2+}$, and $\mathrm{y} 24^{3+}-$ y26 $6^{3+}$. Curiously, satellite ions with neutral $\mathrm{NH}_{3}$ or $\mathrm{H}_{2} \mathrm{O}$ losses were not detected within this range.

\subsubsection{The Evaluation of Identification Accuracy}

Mass accuracy was assessed via mass error. The measured isotopic mass and the mass error for each free insulin chain are presented in Table 1. Note that the 


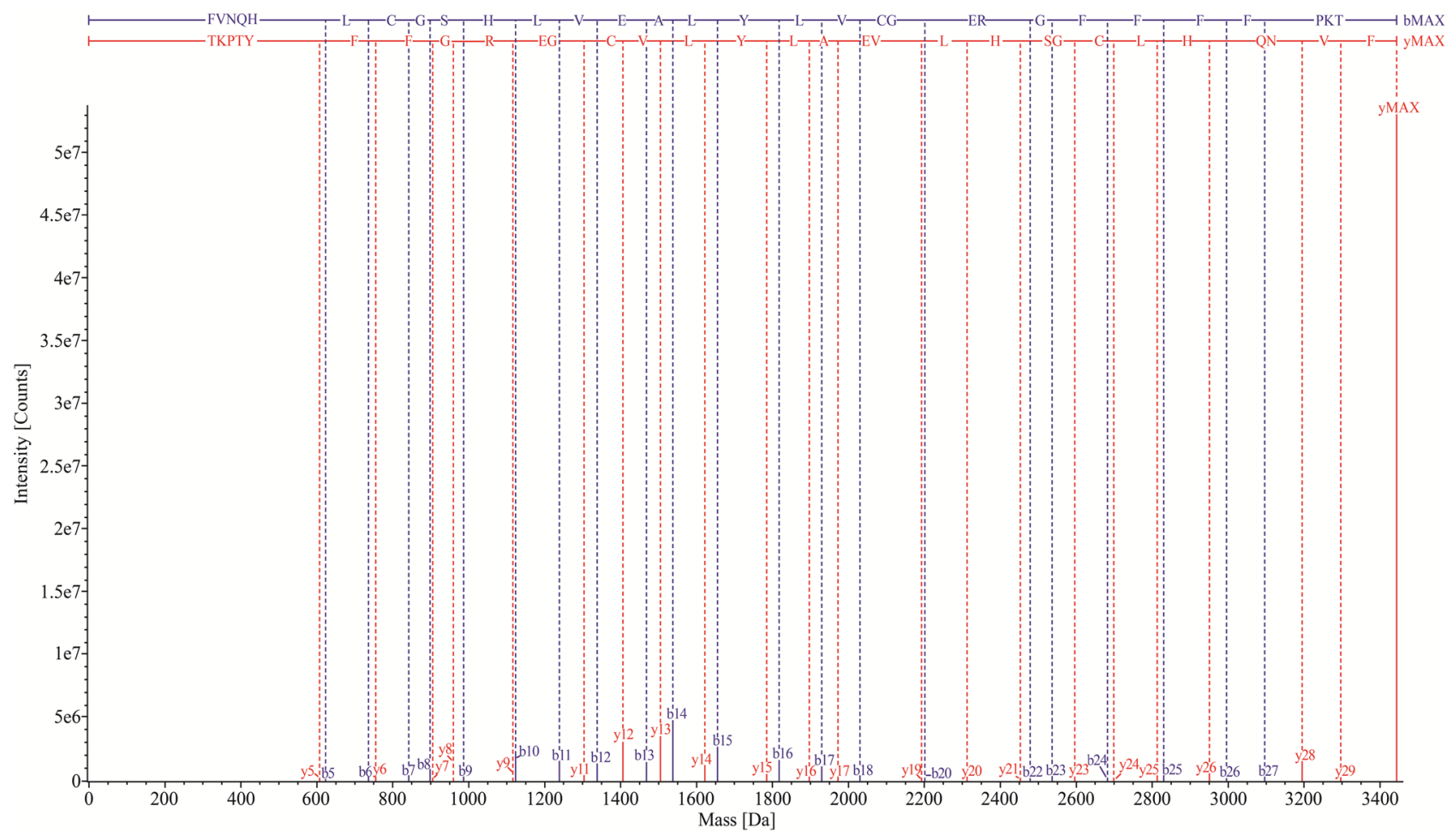

Figure 9. The fragmentation ion mapping of isolated human insulin B-chain peptide.

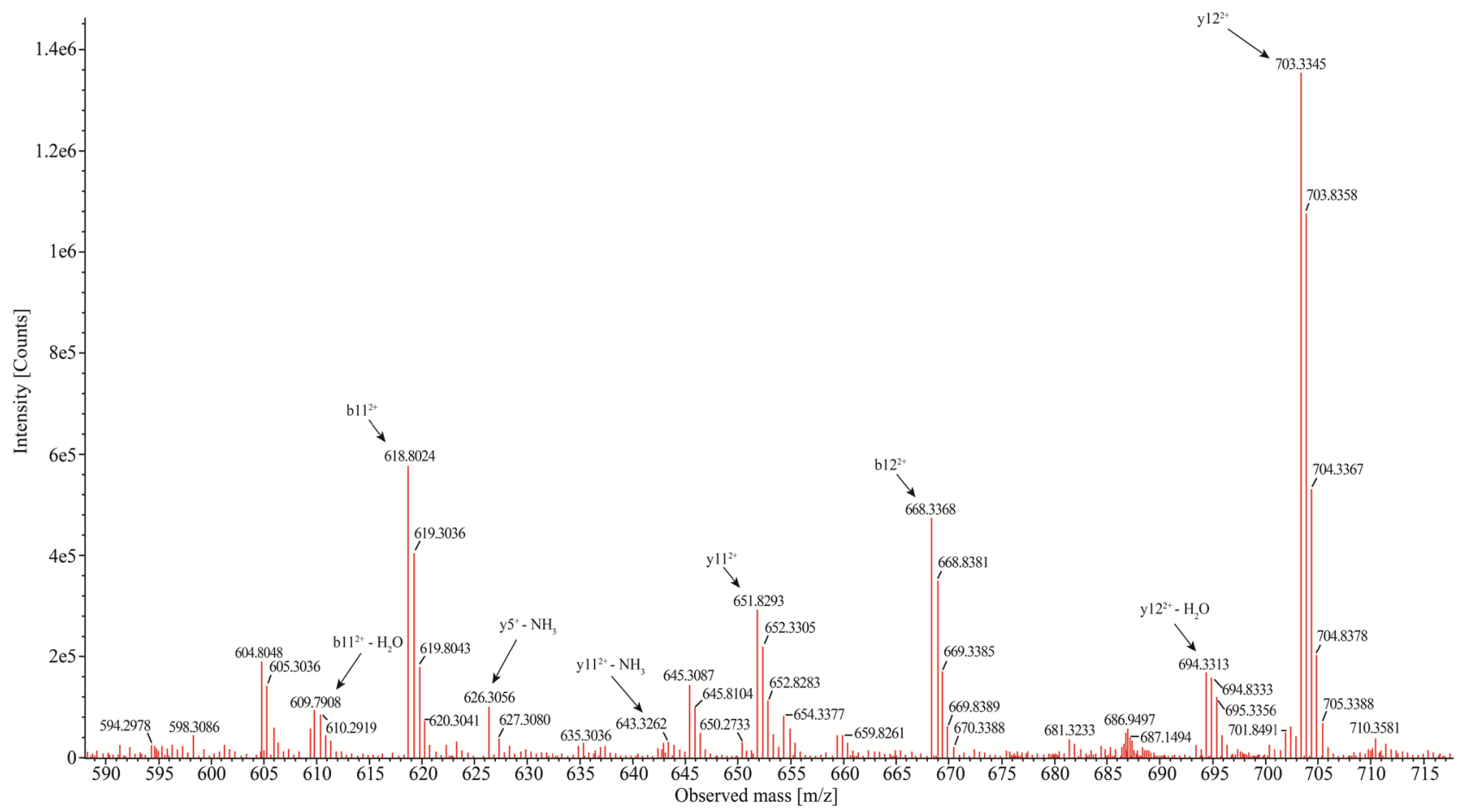

Figure 10. The identification of daughter ion clusters for free human insulin B-chain ranging between $590 \mathrm{~m} / \mathrm{z}$ and $715 \mathrm{~m} / \mathrm{z}$. 


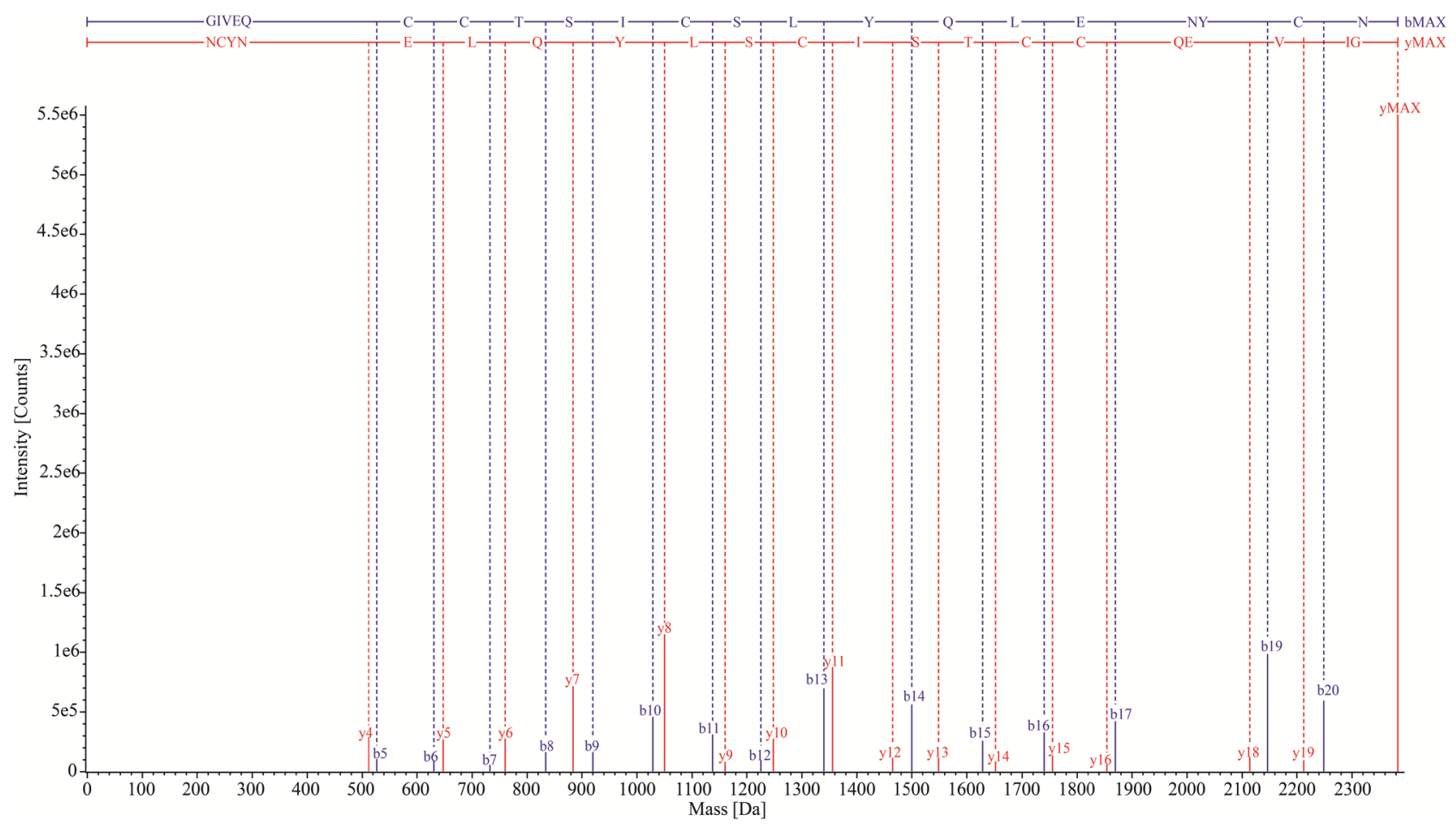

Figure 11. The fragmentation ion mapping of recombinant insulin aspart A-chain.

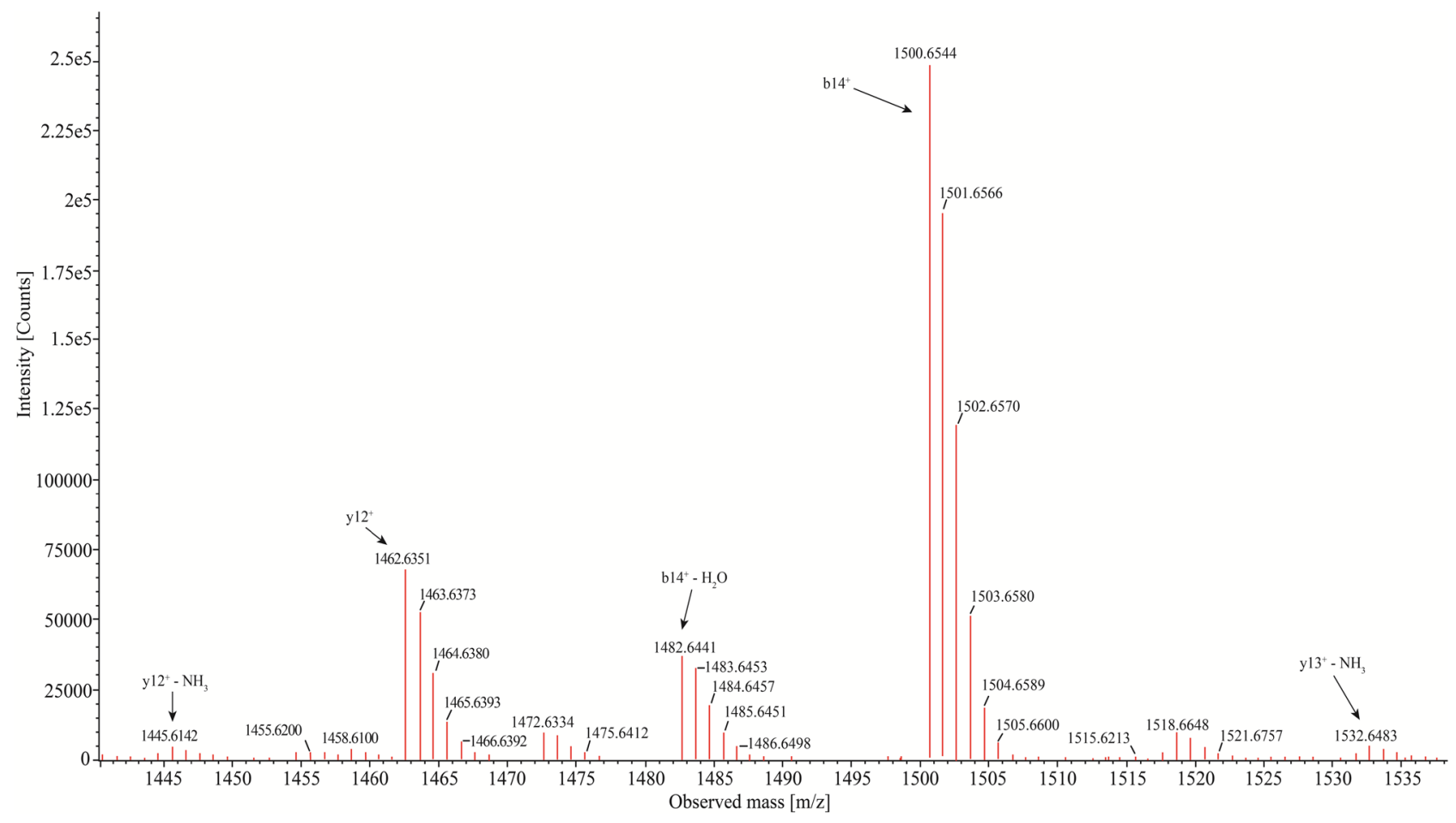

Figure 12. The discerning of daughter ion clusters for free insulin aspart A-chain ranging from $1445 \mathrm{~m} / \mathrm{z}$ to $1535 \mathrm{~m} / \mathrm{z}$. 


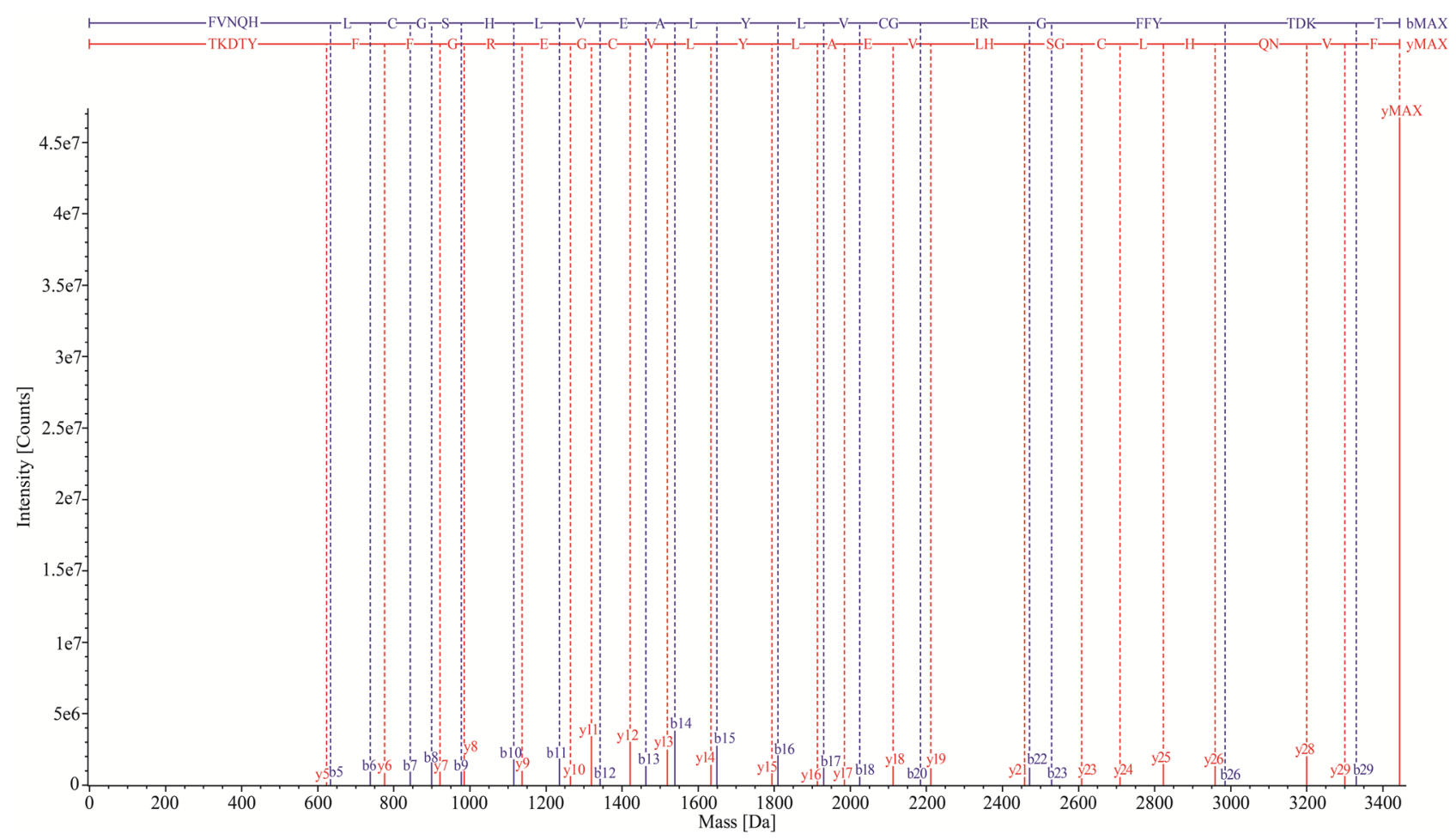

Figure 13. The fragmentation ion map of recombinant insulin aspart B chain.

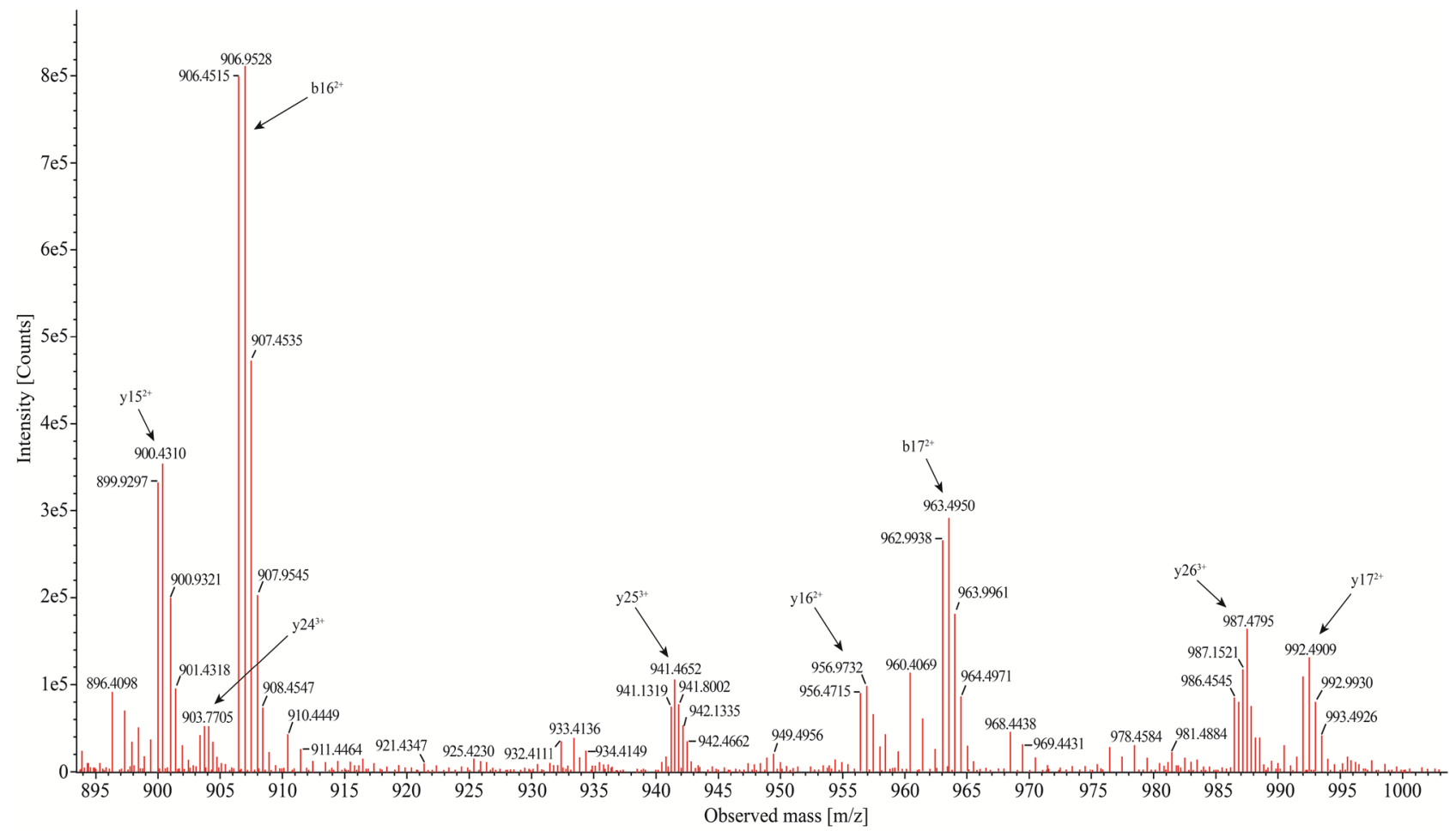

Figure 14. The identification of daughter ion clusters for free insulin aspart B chain ranging from $895 \mathrm{~m} / \mathrm{z}$ to $1000 \mathrm{~m} / \mathrm{z}$. 
Table 1. The observed mass and the mass accuracy for each isolated insulin peptide chain.

\begin{tabular}{ccccc}
\hline \multicolumn{1}{c}{ Peptide name } & Peptide sequence & Expected mass $(\mathrm{Da})$ Measured mass $[\mathrm{M}+\mathrm{H}]^{+}(\mathrm{Da})$ & Mass error $(\mathrm{ppm})$ \\
\hline Human insulin A chain & GIVEQCCTSICSLYQLENYCN & 2382.0001 & 2383.0117 & 1.8 \\
Human insulin B chain & FVNQHLCGSHLVEALYLVCGERGFFYTPKT & 3427.6846 & 3428.7033 & 3.3 \\
Insulin aspart A chain & GIVEQCCTSICSLYQLENYCN & 2382.0001 & 2383.0080 & 0.3 \\
Insulin aspart B chain & FVNQHLCGSHLVEALYLVCGERGFFYTDKT & 3445.6588 & 3446.6760 & 2.9 \\
\hline
\end{tabular}

criterion for mass accuracy defined by USP is $500 \mathrm{ppm}$. The results showed that the mass error for each peptide chain was below both the in-house criterion (i.e., $10 \mathrm{ppm}$ ) and USP standard, indicating that the mass accuracy was highly satisfactory.

\section{Conclusion}

For this study, recombinant human insulin and insulin aspart were analyzed using the ESI-QToF technique. The results showed that nearly all the necessary fragmentation ion information could be obtained through de novo sequencing. However, discriminating between leucine and isoleucine was challenging using this tandem MS/MS system. Therefore, an additional dimension of separation (e.g., using an ion mobility spectrometer) may be necessary. The observed mass error was also deficient, suggesting that Unify can accurately interpret the sequencing data. Therefore, this method shows great potential for the identification of recombinant human insulin and the analogue products during quality control and drug development.

\section{Conflicts of Interest}

The author declares no conflicts of interest regarding the publication of this paper.

\section{References}

[1] Lavalle-González, F.J. and Khatami, H. (2014) The Biosimilar Insulin Landscape: Current Developments. Postgraduate Medicine, 126, 81-92. https://doi.org/10.3810/pgm.2014.10.2823

[2] Pontes, C.E.C., Gouvea Barroso, W.B. and da Nóbrega Rito, P. (2019) Market for Biotechnology Drugs: Market Analysis of Insulin. Journal of Pharmaceutical Health Services Research, 10, 219-226. https://doi.org/10.1111/jphs.12278

[3] Ladisch, M.R. and Kohlmann, K.L. (1992) Recombinant Human Insulin. Biotechnology Progress, 8, 469-478. https://doi.org/10.1021/bp00018a001

[4] Heinemann, L. (2016) Biosimilar Insulin and Costs: What Can We Expect? Journal of Diabetes Science and Technology, 10, 457-462. https://doi.org/10.1177/1932296815605337

[5] White, J. and Goldman, J. (2019) Biosimilar and Follow-on Insulin: The Ins, Outs, and Interchangeability. Journal of Pharmacy Technology, 35, 25-35. https://doi.org/10.1177/8755122518802268 
[6] Owens, D.R., Landgraf, W., Schmidt, A., Bretzel, R.G. and Kuhlmann, M.K. (2012) The Emergence of Biosimilar Insulin Preparations-A Cause for Concern? Diabetes Technology \& Therapeutics, 14, 989-996. https://doi.org/10.1089/dia.2012.0105

[7] Peters, A.L., Pollom, R.D., Zielonka, J.S., Carey, M.A. and Edelman, S.V. (2015) Biosimilars and New Insulin Versions. Endocrine Practice, 21, 1387-1394. https://doi.org/10.4158/EP14595.RA

[8] Frost, H. (2005) Antibody-Mediated Side Effects of Recombinant Proteins. Toxicology, 209, 155-160. https://doi.org/10.1016/j.tox.2004.12.028

[9] Malucchi, S. and Bertolotto, A. (2008) Clinical Aspects of Immunogenicity to Biopharmaceuticals. In: Weert, M., Møller, E.H., et al., Eds., Immunogenicity of Biopharmaceuticals. Biotechnology: Pharmaceutical Aspects, Springer, New York, 27-56. https://doi.org/10.1007/978-0-387-75841-1 2

[10] Petrides, D., Sapidou, E. and Calandranis, J. (1995) Computer-Aided Process Analysis and Economic Evaluation for Biosynthetic Human Insulin Production-A Case Study. Biotechnology and Bioengineering, 48, 529-541. https://doi.org/10.1002/bit.260480516

[11] Sahoo, N., Choudhury, K. and Manchikanti, P. (2009) Manufacturing of Biodrugs. BioDrugs, 23, 217-229. https://doi.org/10.2165/11317110-000000000-00000

[12] Hjorth, C.F., Hubálek, F., Andersson, J., Poulsen, C., Otzen, D. and Naver, H. (2015) Purification and Identification of High Molecular Weight Products Formed During Storage of Neutral Formulation of Human Insulin. Pharmaceutical Research, 32, 2072-2085. https://doi.org/10.1007/s11095-014-1600-3

[13] Rotenstein, L.S., Ran, N., Shivers, J.P., Yarchoan, M. and Close, K.L. (2012) Opportunities and Challenges for Biosimilars: What's on the Horizon in the Global Insulin Market? Clinical Diabetes, 30, 138-150. https://doi.org/10.2337/diaclin.30.4.138

[14] European Medicines Agency (2017) Biosimilars in the EU: Information Guide for Healthcare Professionals. European Medicines Agency and the European Commission.

[15] Standing, K.G. (2003) Peptide and Protein De Novo Sequencing by Mass Spectrometry. Current Opinion in Structural Biology, 13, 595-601.

https://doi.org/10.1016/j.sbi.2003.09.005

[16] Thevis, M., Thomas, A. and Schänzer, W. (2008) Mass Spectrometric Determination of Insulins and Their Degradation Products in Sports Drug Testing. Mass Spectrometry Reviews, 27, 35-50. https://doi.org/10.1002/mas.20154

[17] Burns, J.A., Butler, J.C., Moran, J. and Whitesides, G.M. (1991) Selective Reduction of Disulfides by Tris (2-Carboxyethyl) Phosphine. The Journal of Organic Chemistry, 56, 2648-2650. https://doi.org/10.1021/jo00008a014

[18] Cline, D.J., Redding, S.E., Brohawn, S.G., Psathas, J.N., Schneider, J.P. and Thorpe, C. (2004) New Water-Soluble Phosphines as Reductants of Peptide and Protein Disulfide Bonds: Reactivity and Membrane Permeability. Biochemistry, 43, 15195-15203. https://doi.org/10.1021/bi048329a

[19] Gray, W.R. (1993) Disulfide Structures of Highly Bridged Peptides: A New Strategy for Analysis. Protein Science, 2, 1732-1748. https://doi.org/10.1002/pro.5560021017

[20] Thevis, M., Thomas, A., Delahaut, P., Bosseloir, A. and Schänzer, W. (2005) Qualitative Determination of Synthetic Analogues of Insulin in Human Plasma by Immunoaffinity Purification and Liquid Chromatography-Tandem Mass Spectrometry for Doping Control Purposes. Analytical Chemistry, 77, 3579-3585.

https://doi.org/10.1021/ac050066i 
[21] Blackburn, M. (2013) Advances in the Quantitation of Therapeutic Insulin Analogues by LC-MS/MS. Bioanalysis, 5, 2933-2946. https://doi.org/10.4155/bio.13.257

[22] Thevis, M., Thomas, A., Delahaut, P., Bosseloir, A. and Schänzer, W. (2006) Doping Control Analysis of Intact Rapid-Acting Insulin Analogues in Human Urine by Liquid Chromatography-Tandem Mass Spectrometry. Analytical Chemistry, 78, 1897-1903. https://doi.org/10.1021/ac052095z

[23] Thomas, A., Schänzer, W. and Thevis, M. (2014) Determination of Human Insulin and Its Analogues in Human Blood Using Liquid Chromatography Coupled to Ion Mobility Mass Spectrometry (LC-IM-MS). Drug Testing and Analysis, 6, 1125-1132. https://doi.org/10.1002/dta.1710

[24] Asbury, G.R. and Hill Jr., H.H. (2000) Evaluation of Ultrahigh Resolution Ion Mobility Spectrometry as an Analytical Separation Device in Chromatographic Terms. Journal of Microcolumn Separations, 12, 172-178.

https://doi.org/10.1002/(SICI)1520-667X(2000)12:3<172::AID-MCS7>3.0.CO;2-W 